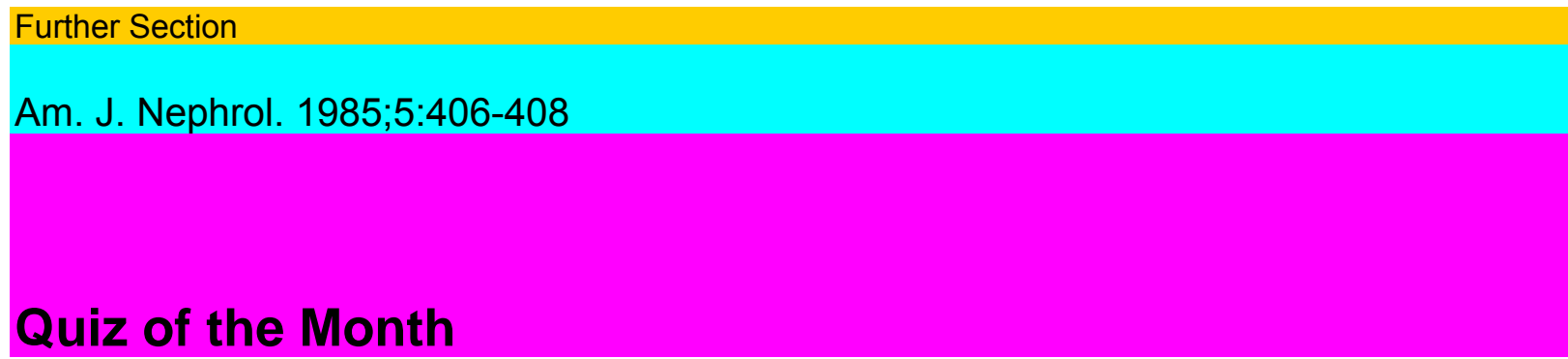

Answer to Question 1 \& Question 2

Additional laboratory studies demonstrated an anti-hyaluronidase titer of 1:2,048 U (normal < 1:128 $\mathrm{U}$ ) and an anti-DNAse B titer of 1:680 $\mathrm{U}$ (normal $<85 \mathrm{U}$ ), suggesting the possibility of postinfectious (streptococcal) glomerulonephritis (PGN). The presence of nephrotic-range proteinuria does not militate against the diagnosis, since nephrotic syndrome may occur in PGN [1].

The 17 glomeruli in the renal biopsy showed an acute diffuse proliferative glomerulonephritis. Glomerular capillary lumens were narrowed by a combination of swollen and proliferated endothelial cells, hypertrophied mesangial cells, and polymorphonuclear leukocytes (fig. 1), and the involvement of glomeruli was quite uniform. An occasional 'hump' was seen along the outer surface of the glomerular capillaries (fig. 1, inset). No crescents were seen, and the arteries and interstitium were unremarka-

ble. These findings are typical light microscopic features of PGN [1-3]. It is interesting to note that occasional small crescents may be found in PGN, but that large circumferential crescents involving a majority of glomeruli are unusual in this disease [1].

Electron microscopy confirmed the presence of scattered subepithelial electron-dense 'humps' along the capillary wall (fig. 2). Subendothelial, intramembranous, and mesangial deposits were also seen and have been previously reported in PGN [4]. Epithelial cell foot processes were extensively obliterated. Granular deposits of C3 and, to a lesser extent, IgG and Clq were seen along the capillary walls by immunofluorescence microscopy. While IgG may be the most intense immunoreactant seen in these cases, some cases of PGN show only C3 [5].

Fig 1. Light micrograph of a glomerulus showing moderate endocapillary/mesangial cell hypercellularity. $\times 250$. In the inset a hump-like deposit (arrowhead) is seen on the outer surface of a capillary loop. X 500.

Fig. 2. Elctron micrograph of a glomerulus. Subepithelial electron-dense 'humps' are present along the capillary basement mambrane. X 9,000.

Quiz of the Month

407

\title{
eferences
}

1 Baldwin, D.S.; Gluck, M.S.; Schacht, R.G.; Gallo, G.: The long-term course of poststreptococcal glomerulonephritis. Ann. intern. Med. 80: 342-358 (1979).

2 Heptinstall, R.H.: Pathology of the kidney; 3rd ed. (Little, Brown, Boston 1983).

3 Jennings, R.B.; Earle, D.P.: Poststreptococcal glomerulonephritis: histopathologic and clinical studies of the acute, subsiding acute, and early chronic latent phases. J. clin. Invest. 40: 1525-1595(1961).

4 Lewy, J.E.; Salinas-Madrigal, L.; Herdson, P.B.; Pirani, C.L.; Metcoff, J.: Clinocopathologic correlations in acute poststreptococcal glomerulonephritis. Medicine, Baltimore 50: 453-501 (1971).

5 Fish, A.J.; Herdman, R.C.; Michael, A.F.; Pickering, R.J.; Good, R.A.: Epidemic acute glomerulonephritis associated with type 49 streptococcal pyoderma. Am. J. Med. 48: 29-39 (1970). 


\section{Answer to Question 2}

Light microscopic examinationof the biopsy showed focal proliferative glomerulonephritis with crescents involving 8 (13\%) of 62 glomeruli (fig. 1). One arteriole showed hyaline changes; no unequivocal vasculitis was seen, and tubules and interstitium were unremarkable.

Electron microscopy demonstrated mesangial electron-dense deposits (fig. 2), increased mesangial matrix and cells, segmental endothelial cell sloughing and capillary loop collapse, and fibrin tactoids in Bowman's space. Epithelial cell foot processes were extensively obliterated.

By immunofluorescence microscopy, glomeruli showed IgA and, to a lesser extent, C3 and IgG in a diffuse mesangial pattern. Segmental and focal staining for

fibrin(ogen)-related antigen was also noted. These results support a diagnosis of IgA nephropathy (Berger's disease).

In retrospect, the patient recalled several episodes of gross hematuria over the year prior to hospitalization. The case, therefore, illustrates the usual presentation of IgA nephropathy which is that of recurrent gross or microscopic hematuria in a young man [1]. These episodes are usually precipitated by and synchronous with upper respiratory tract infections. Although moderate proteinuria $(<2 \mathrm{~g} / 24 \mathrm{~h}$ ) is the rule, approximately $10 \%$ of patients may show nephrotic-range ( $>$ $3.5 \mathrm{~g} / 24 \mathrm{~h}$ ) proteinuria, as was the case here [2]. Hypertension and, on occasion, acute or chronic renal failure may occur [3].

“*äm*.

Fig. 1. Light microscopic appearance of two glomeruli from the biopsy. A crescent partially fills Bowman's space of one glomerulus. X 160 .

$j i^{1} / 0^{\prime} £$

ig. 2. Electron microscopy of a glomerulus showing the presence of mesangial electron-dense deposits (arrowhead). $\times 6,500$.

08

uiz of the Month

The biopsy findings were very pleomorphic. The glo-meruli may be essentially normal by light microscopy, may on occasion show diffuse crescentic glomerulone-phritis, but most often demonstrate mesangial hypercel-lularity or focal crescentic glomerulonephritis. Rarely, a membranous or mesangiocapillary pattern may be seen [2]. Electron microscopy characteristically shows mesangial electron-dense deposits; small subendothelial or sub-epithelial deposits are present in a minority of cases [1, 3]. Fragmentation and thinning of the lamina densa has also been described [4]. The immunofluorescence microscopy is diagnostic. IgA is the most intense immuno-reactant; smaller amounts of IgG, C3, Clq, IgM, proper-din, and fibrin(ogen)-related antigen may accompany it [31.

\section{References}

1 Clarkson, A.R.; Seymour, A.E.; Thompson, A.J.; Haynes, W.D.G.; Chan, Y.L.; Jackson, B.: IgA nephropathy: a syndrome of uniform morphology, diverse clinical features, and uncertain prognosis. Clin. Nephrol. 8: 459-471 (1977). 
2 Nakamoto, Y.; Asano, Y.; Dohi, K.; Fujioka, M.; Iida, H.; Kida, H.; Kibe, Y.; Hattori, N.; Takeuchi, J.: Primary IgA glomerulonephritis and Schönlein-Henoch purpura nephritis: clinicopatho-logical and immunohistological characteristics. Q. Jl Med. 47: 495-516(1978).

3 Hogg, R.J.; Silva, F.: A multicenter study of IgA nephropathy in children. A report of the Southwest Pediatric Nephrology Study Group. Kidney int. 22: 643-652 (1982).

4 Shigematsu, H.; Kobayashi, Y.; Tateno, S.; Hiki, Y.; Kuwao, S.: Ultrastructural glomerular loop abnormalities in IgA nephritis. Nephronift· 1-7 (1982). 